\title{
(2) OPEN ACCESS \\ Anticipatory prescribing in community end-of-life care in the UK and Ireland during the COVID-19 pandemic: online survey
}

\author{
Bárbara Antunes (D) , Ben Bowers (D) , ${ }^{1}$ Isaac Winterburn, ${ }^{1}$ \\ Michael P Kelly, ${ }^{1}$ Robert Brodrick, ${ }^{2,3}$ Kristian Pollock, ${ }^{4}$ Megha Majumder, ${ }^{1}$ \\ Anna Spathis, ${ }^{1}$ lain Lawrie, ${ }^{5,6}$ Rob George, ${ }^{7,8}$ Richella Ryan, ${ }^{1,2}$ \\ Stephen Barclay (D) ${ }^{1}$
}

- Additional material is published online only. To view please visit the journal online (http://dx.doi.org/10.1136/ bmjspcare-2020-002394).

For numbered affiliations see end of article.

\section{Correspondence to}

Bárbara Antunes, Department of Public Health and Primary Care, University of Cambridge Primary Care Unit, Cambridge CB2 OSR, Cambridgeshire, UK; bc521@medschl.cam.ac.uk

Received 30 April 2020 Accepted 1 June 2020 Published Online First 16 June 2020

\section{A Check for updates}

(C) Author(s) (or their employer(s)) 2020. Re-use permitted under CC BY-NC. No commercial re-use. See rights and permissions. Published by BMJ.

To cite: Antunes B, Bowers B, Winterburn I, et al. BMJ Supportive \& Palliative Care 2020:10:343-349.

\section{ABSTRACT}

Background Anticipatory prescribing (AP) of injectable medications in advance of clinical need is established practice in community endof-life care. Changes to prescribing guidelines and practice have been reported during the COVID-19 pandemic.

Aims and objectives To investigate UK and Ireland clinicians' experiences concerning changes in AP during the COVID-19 pandemic and their recommendations for change.

Methods Online survey of participants at previous AP national workshops, members of the Association for Palliative Medicine of Great Britain and Ireland and other professional organisations, with snowball sampling.

Results Two hundred and sixty-one replies were received between 9 and 19 April 2020 from clinicians in community, hospice and hospital settings across all areas of the UK and Ireland. Changes to AP local guidance and practice were reported: route of administration (47\%), drugs prescribed (38\%), total quantities prescribed (35\%), doses and ranges (29\%). Concerns over shortages of nurses and doctors to administer subcutaneous injections led $37 \%$ to consider drug administration by family or social caregivers, often by buccal, sublingual and transdermal routes. Clinical contact and patient assessment were more often remote via telephone or video (63\%). Recommendations for regulatory changes to permit drug repurposing and easier community access were made.

Conclusions The challenges of the COVID-19 pandemic for UK community palliative care has stimulated rapid innovation in AP. The extent to which these are implemented and their clinical efficacy need further examination.

\section{INTRODUCTION}

Anticipatory prescribing (AP) is the prescribing and dispensing of injectable medications in advance of clinical need, for visiting nurses or doctors to give as required if symptoms (pain, nausea and vomiting, agitation and respiratory tract secretions and breathlessness) arise in the final days of life. ${ }^{1-3}$ AP may optimise symptom control for deaths in the community ${ }^{1-8}$ : it is well established and widely recommended in the UK, New Zealand and Australia, ${ }^{1-3}$ 9-12 and less commonly in the USA, Singapore and Norway. ${ }^{13-16}$

The number of people dying in care homes and at home has risen dramatically during the COVID-19 pandemic in the UK and in many other countries. ${ }^{17} 18$ AP guidance and practice has changed in response. ${ }^{15-7} 19$ There is alarm about depleted drug stocks and that nurses and doctors may not be readily available to give injections. ${ }^{5}$ Recent UK guidance proposed both family caregiver administration and use of different drug formulations via the buccal, rectal or sublingual routes along with traditional subcutaneous injections. ${ }^{5-7} 21$

The evidence base for current AP practice is sparse, $2391622-26$ even more so for the buccal or sublingual routes, which are based primarily on professional experience and within paediatric palliative care. $^{13-1527}$

Family caregivers have rarely administered AP medications in the UK. ${ }^{27-29}$ Australian experience suggests family caregivers appreciate being able to provide symptom relief: some struggle with the responsibility ${ }^{10} 30 \quad 31$ and/or 
worry it is a form of euthanasia. ${ }^{10}$ Media concerns have focused on family caregivers having a great responsibility but without adequate training or oversight. $^{20}$

To support practitioners and policy-makers, we surveyed UK/Ireland professionals and investigated how AP practice has changed in response to revised national guidance and local demands during the COVID-19 pandemic.

\section{Aims and research questions}

With regard to AP practice during the COVID-19 pandemic, what do practitioners report in relation to

1. Changes in drug prescription?

2. Changes in drug administration?

3. Changes in support structures for AP?

4. Suggestions for further changes?

\section{METHODS}

An online survey (see online supplementary appendix) was developed in Survey Monkey based on the literature, our own clinical experience and SB's recent correspondence with palliative care and primary care colleagues across the UK. The study was reviewed by the University of Cambridge Psychology Research Ethics Committee (PRE.2019.013)

After a local pilot, an email with the survey link was sent between 8 and 13 April 2020 to delegates who attended AP workshops in 2019 for doctors, nurses and pharmacists in palliative and primary care; members of the Association for Palliative Medicine of Great Britain and Ireland, the National Institute for Health and Social Care Excellence Medicines Associate Programme and Resilient GP Facebook Group, UK Queen's Nursing Institute. Colleagues were encouraged to forward the survey link to interested colleagues, seeking a snowball sample of practitioners. ${ }^{32}$

All fields were mandatory and responses were anonymous unless respondents supplied their name and email address in the optional final field to indicate interest in a follow-up telephone interview.

Questions 1-4 sought demographic data concerning respondents' geographical areas of work, professional roles, clinical work settings and involvement in AP. Question 5 addressed changes in AP practice (if any) during the COVID-19 pandemic. These included drug types prescribed, total quantities dispensed, drug doses/ranges, drugs and support documents in home/ care home, route of administration especially sublingual/buccal, persons administering AP drugs (especially family or social care colleagues), advice and support for non-clinical administration, phone or video support, prescribing in non-COVID-related illness and syringe driver use. Reasons for any changes in practice were invited in free text. Question 6 invited comments and suggestions for changes in practice, policy and legislation to optimise AP.

\section{Data analysis}

The Checklist for Reporting Results of Internet E-Surveys was followed. ${ }^{33}$ Descriptive statistics were used for demographic and categorical response data. For freetext replies to Questions 5 and 6, BA, BB, IW and SB developed themes inductively from the data, allocating responses to themes developed for each subquestion. ${ }^{34}$ These are presented with illustrative quotations.

\section{RESULTS}

\section{Respondents}

Two hundred and sixty-one replies were received between 9 and 19 April 2020, from palliative medicine consultants (CONS 97, 37\%), general practitioners (GP 63, 24\%), palliative care specialist nurses (CNS $31,12 \%)$, general community nurses $(8,7 \%)$, palliative medicine trainees $(15,6 \%)$, other doctors (12, $5 \%)$, pharmacists $(5,2 \%)$, other nurses $(4,2 \%)$ and other professional group $(16,6 \%)$. The geographical distribution of respondents is shown in figure 1.

Clinical work settings were community specialist palliative care (144, 55\%), hospice inpatient unit (104, $40 \%)$, community primary care $(96,37 \%)$, hospital $(87,33 \%)$, care home $(29,11 \%)$ and other settings $(7$, $3 \%)$. All respondents were working clinically. Participants' involvement in the AP process were decision to prescribe $(239,92 \%)$, prescribing $(225,86 \%)$, dispensing $(12,5 \%)$, monitoring before drug administration $(99,38 \%)$, medication administration (53, $20 \%)$ and medication disposal after death (13, 5\%).

\section{Changes in AP practice}

Respondents' reports of any changes in AP practice in their area, with examples from thematic analysis of the explanatory free text, are listed in table 1.

Marked changes in AP were reported by about onethird in most domains. Changes in route of administration (47\%) and drugs prescribed (38\%) were associated with consideration of buccal, sublingual and transdermal routes and avoidance of subcutaneous injections. These related to possible administration by family or social caregivers (37\%) and drug availability. Changes in quantities prescribed (35\%) and doses/ranges (29\%) reflected the reported needs of some dying with COVID-19 for higher doses and more frequent administration to control symptoms than previously (and to protect limited medication supplies). Changes were under way to facilitate drug delivery and relevant paperwork to the home (36\%).

At the same time, clinical contact and patient assessment were changing to telephone or video rather than in person (63\%). Telephone advice was more available (49\%). Changes in prescribing for non-COVID-19 terminal illness (24\%) reflected moves towards noninjectable routes and concern that they might develop COVID-19 and associated severe agitation. Planned reductions in syringe driver use (30\%) reflected perceptions that the COVID-19 terminal phase is brief 


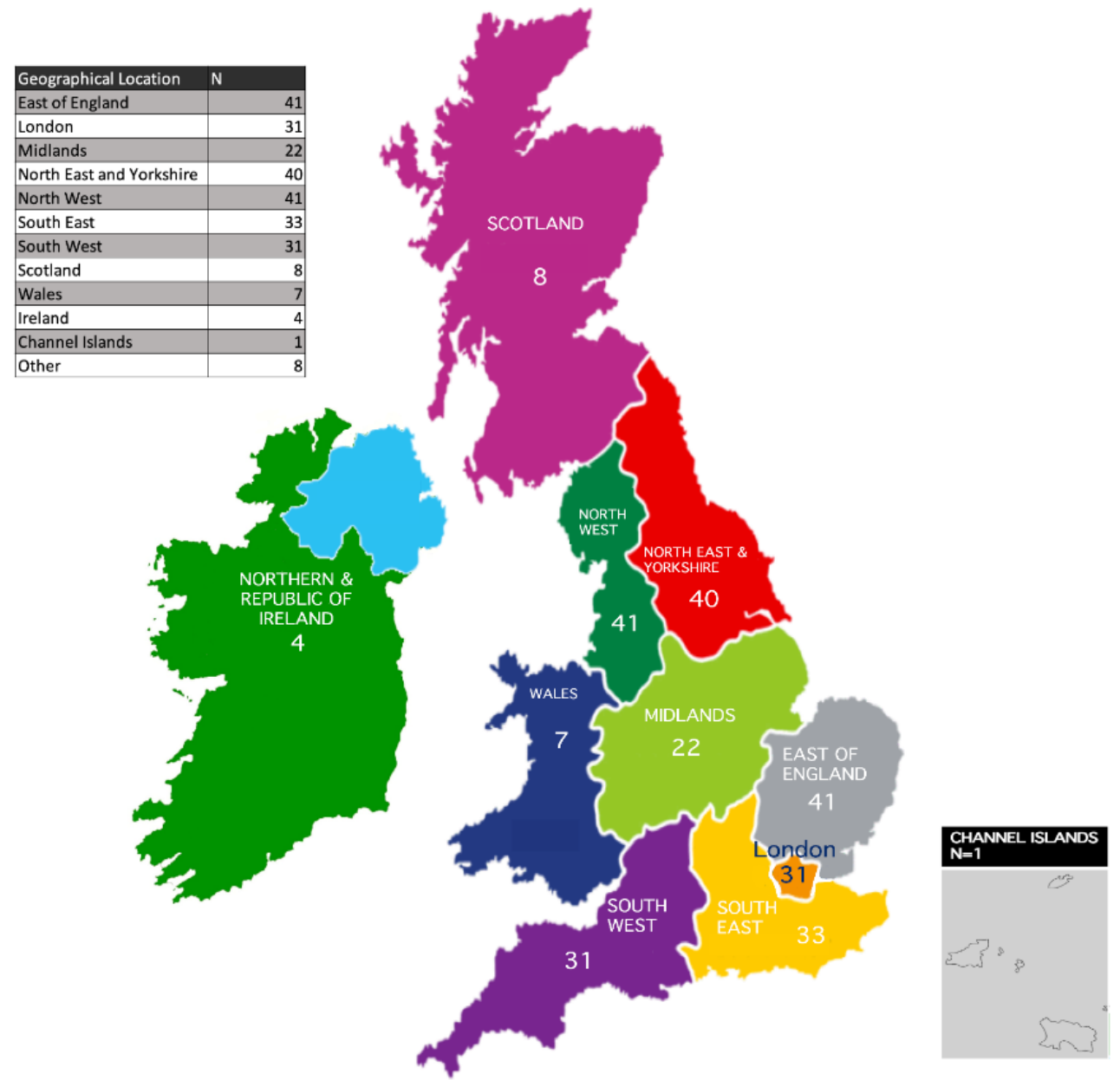

Figure 1 Distribution of responders across Great Britain and Ireland.

and best managed with 'as needed' individual doses and that both district nurses and syringe drivers might be in short supply.

\section{Practitioners' comments and suggestions for change}

The dominant themes were calls for three changes in pharmaceutical legislation.

Permit repurposing of prescribed AP drugs in care homes

Allowing care homes to re-use AP medications when the patient has died and the drugs have not been used. Such a waste of meds. \#209 CONS

COVID outbreak in nursing home we care for. Would be very useful if could re-use Anticipatory subcutaneous medications and also if the nursing home could hold a small supply. \#227 GP

\section{Enable wider ready access to drugs in the community}

Nursing homes have asked for spare sets of anticipatory medications should patients unexpectedly become unwell, but this is not within the law. \#142 GP

It would be really helpful to have a centralised stock of AP drugs (maybe with community nursing teams) so that each patient just has what they need dispensed when they need it. \#170 GP

Having access 24 hours for anticipatory meds: prescription and meds in key localities to enable rapid response and symptom control. \#119 CNS

\section{Permit recycling of drugs returned to pharmacies}

Enable unused vials to be taken back to pharmacy and reused. Fear of waste and cost are factors that limit the amount of AP in the community. \#245 CONS

This is our opportunity to secure legislative change for the establishment of centralised supplies, the ability for clinical staff to have sensible safe boxes and for the return of safe, unused drugs to pharmacies ... This is a known and appalling waste that must stop now and be permanent. There has never been a cogent justification. \#100 CONS

\section{DISCUSSION}

This study revealed rapid change in AP practice is under consideration in many areas of the UK/Ireland: increased use of alternative routes, changes in drugs prescribed to address stock shortages, new routes of 
Table 1 AP practice changes during COVID-19

\begin{tabular}{|c|c|c|c|c|}
\hline Changes to & Yes & No & Unsure & Illustrative comment examples \\
\hline Which drugs are prescribed? & $98(38 \%)$ & $146(56 \%)$ & $17(7 \%)$ & $\begin{array}{l}\text { More off-licence drug use \#83 CONS. } \\
\text { Including non-injectables, for example, buccal midazolam in case } \\
\text { no nurse can attend \#14 CONS. } \\
\text { Changing with availability: hyoscine patch for glycopyrronium } \\
\text { \#253 CNS. }\end{array}$ \\
\hline The quantities of drugs prescribed? & $90(35 \%)$ & $137(53 \%)$ & $34(13 \%)$ & $\begin{array}{l}\text { Prescribing smaller quantities to preserve stocks \#51 CONS. } \\
\text { Larger doses for ARDS: may need repeated sooner \#127 TRAIN. } \\
\text { Continuing normal practice \#217 DOC. }\end{array}$ \\
\hline Drug doses/dose ranges prescribed? & $75(29 \%)$ & $163(63 \%)$ & $23(9 \%)$ & $\begin{array}{l}\text { Higher starting doses for distress, especially levomepromazine } \\
\text { \#241 CONS. } \\
\text { Up to 1-hourly if dyspnoea or distress persist \#102 CONS } \\
\text { Quicker escalation to larger doses for some \#99 GP. } \\
\text { Wider ranges and more prescribed to cover every eventuality } \\
\text { \#83 CONS. }\end{array}$ \\
\hline $\begin{array}{l}\text { Arrangements for drugs and supporting } \\
\text { documents to be in the home/care home? }\end{array}$ & $96(36 \%)$ & $135(52 \%)$ & $31(12 \%)$ & $\begin{array}{l}\text { Authorisation sheet electronic \#240 GP } \\
\text { 'Grab bags' with anticipatory meds available in emergency } \\
\text { department \#248 CONS. } \\
\text { Stores with army to deliver: 'just in case' changed to 'just in } \\
\text { time' \#134 CONS. }\end{array}$ \\
\hline $\begin{array}{l}\text { Route of administration, especially the } \\
\text { sublingual/buccal route? }\end{array}$ & $122(47 \%)$ & $124(48 \%)$ & $15(6 \%)$ & $\begin{array}{l}\text { Oral/buccal routes give patients/relative more control without } \\
\text { HCP \#84 CONS. } \\
\text { Subcutaneous route first, buccal/transdermal use if availability of } \\
\text { SC drugs affected \#64 CNS. } \\
\text { Lorazepam, hyoscine and fentanyl patches alternatives if SC } \\
\text { meds not available \#5 CONS. }\end{array}$ \\
\hline $\begin{array}{l}\text { Person administering AP drugs, especially } \\
\text { family/informal carers or social care } \\
\text { colleagues? }\end{array}$ & $97(37 \%)$ & $136(52 \%)$ & $28(11 \%)$ & $\begin{array}{l}\text { Family offered chance to learn if they want to \#217 DOC. } \\
\text { Care home staff rather than district nurse after phone advice } \\
\text { \#213 GP. } \\
\text { Already have carer administering SC policy \#244 CONS. }\end{array}$ \\
\hline $\begin{array}{l}\text { Telephone or other advice and support } \\
\text { for AP, including family/social care } \\
\text { administration? }\end{array}$ & $127(49 \%)$ & $113(43 \%)$ & $21(8 \%)$ & $\begin{array}{l}\text { Advice line 17:00-21:00. Increased our cover on weekend and } \\
\text { Bank Holiday \#10 CNS. } \\
\text { Decision for AP made on FaceTime \#46 OTHER. } \\
\text { Much more remote working now; complete change in practice } \\
\# 150 \text { GP. }\end{array}$ \\
\hline $\begin{array}{l}\text { The use of phone or video to support AP } \\
\text { practice? }\end{array}$ & $165(63 \%)$ & $78(30 \%)$ & $18(7 \%)$ & $\begin{array}{l}\text { Care now via telephone or video including AP advice \#131 DOC. } \\
\text { Reduces risk of transmission and aids completion of forms when } \\
\text { patient dies \#176 GP. } \\
\text { Video review to make decision patient is dying; may need visit in } \\
\text { person \#240 GP. }\end{array}$ \\
\hline $\begin{array}{l}\text { The prescribing of AP medications for } \\
\text { patients with non-COVID-related illness? }\end{array}$ & $63(24 \%)$ & $181(69 \%)$ & $17(7 \%)$ & $\begin{array}{l}\text { Any patient could develop COVID, anticipating higher likelihood } \\
\text { of agitation \#71 TRAIN. } \\
\text { Consider non injectables for non-complex \#22 CONS. } \\
\text { Preparing for how to cope without syringe drivers \#150 GP. }\end{array}$ \\
\hline The use of syringe drivers? & $79(30 \%)$ & $165(63 \%)$ & $17(7 \%)$ & $\begin{array}{l}\text { Few patients with COVID need syringe pumps as they die very } \\
\text { quickly \#240 GP. } \\
\text { Most dying patients with COVID easily managed by stat doses } \\
\text { \#103 CONS. } \\
\text { - Patches due to equipment and DN resources \#39 TRAIN. }\end{array}$ \\
\hline
\end{tabular}

AP, anticipatory prescribing; CNS, palliative care specialist nurse; CONS, palliative medicine consultant; DN, district nurse; DOC, doctor; GP, general practitioner; HCP, health care professional; OTHER, other professional group; TRAIN, palliative medicine trainee.

administration, family caregiver administration; later prescribing of AP drugs and smaller quantities. There were calls to new pharmaceutical regulations to permit repurposing of AP medications in care homes, wider community drug access and recycling unused medications returned to pharmacies. Reflecting broader changes in community end-of-life-care during the pandemic, more end-of-life care in general and AP in particular is undertaken remotely and electronically, with increased 24 hours availability. These changes will potentially significantly affect care during the pandemic and in the future.
The main strengths of this study were the large number of responses, the broad distribution of replies from across the UK and Ireland and the contemporaneous data. Anonymity encouraged candid responses. It is not possible to calculate a response rate due to the snowball sampling.

Major changes are under way in routes of AP drug administration; community adult end-of-life care practice is increasingly accepting the buccal and sublingual routes. Robust evidence is urgently needed about their pharmacokinetics to develop evidence-based guidelines on suitable drugs, preparations and doses which 
is currently based largely on clinical experience in paediatric palliative care. While transdermal administration is well established, it lacks the flexibility and rapidity of relief when symptoms are unstable in the dying. ${ }^{27}$ This is particularly important for those dying from COVID-19 in whom there is a need for higher drug doses and more frequent administration for effective symptom control.

Many areas are adopting proposals in national policies to consider caregiver drug administration. ${ }^{35}$ This is a big ask for family caregivers with significant risks for their psychological welfare. They may feel pressure to undertake clinical tasks; responsibility for medications heightens anxieties during an already emotional time. ${ }^{1036}$ Nurses often worry about oversedating patients or accelerating death when they give end-of-life medications. ${ }^{323}$ Should a patient die shortly after family caregivers give a medication, they may have even greater concerns. ${ }^{10}{ }^{37}$ Clinicians must be careful whom they approach to undertake these tasks, discuss alternative care options and ensure appropriate training and support is available for willing family caregivers. ${ }^{6} 19283031$ After death, family caregivers confront these worries while being isolated in their grief during the pandemic. ${ }^{19}$

Many palliative care services have responded to the pandemic with extended availability of telephone advice for clinical and social care colleagues, often now including patients and family members. These are welcome developments. The move of much community palliative care to remote video or telephone consultations is understandable due to the need to avoid infection risk to patient, family and clinician. However, this change risks impairing the quality of communication and clinical assessments involved. Video diagnosis of the dying phase and AP decisions, reported by participants, require remote consultation skills that may be more familiar to general practitioners than some working in palliative care services.

Pharmaceutical regulations and policies pertaining to AP in care homes arise from legitimate needs to protect residents from drug errors, particularly with controlled drugs like morphine and midazolam. ${ }^{38} 39$ The presence of suitable medications already in the homes, prescribed for one resident but then urgently needed for another, is frustrating for care home staff and visiting clinicians, as until recently they have been unable to repurpose drugs. Recent UK guidance, issued on 28 April 2020, now permits repurposing in care homes and hospices: this welcome development, called for by many participants, was introduced after data collection was complete. ${ }^{40}$ The related regulations requiring destruction of medications after death and on return to a pharmacy is as yet unresolved. ${ }^{39}$ These tensions are not new but more acute during the pandemic when many care home residents are at risk of dying from COVID-19 and drugs may be in short supply. ${ }^{5}$ A focus on preserving limited drug stocks may delay AP until an individual is close to the end of their life, but risks undermining ready drug availability, which is the essence of AP.

Respondents reported that some dying from COVID-19 have a relatively brief dying phase requiring larger than usual drug doses. This makes current guidance to prescribe drugs in small amounts and close to anticipated death problematic. Community clinicians are conflicted. Wider and more ready community drug access might ease this difficulty but presents legislative and logistical challenges. ${ }^{19}$

\section{CONCLUSIONS}

The COVID-19 pandemic is a challenge to community palliative care. It creates opportunities to innovate rapidly and learn from paediatric palliative care. Given the risk from face-to-face consultations and visits for drug administration, care is now more virtual and remote, with greater dependence on family caregivers to provide care and administer drugs, often via non-injectable routes. These changes are occurring at pace: it remains to be seen how widely they are implemented, how effective they are and how much they will persist after the pandemic. We would welcome collaborations with colleagues across the world to address these important questions.

\section{Author affiliations}

${ }^{1}$ Department of Public Health and Primary Care, University of Cambridge Primary Care Unit, Cambridge, UK

${ }^{2}$ Community Specialist Palliative Care Team, Arthur Rank Hospice Charity, Cambridge, UK

${ }^{3}$ Palliative Medicine, Papworth Hospital NHS Foundation Trust, Cambridge, UK ${ }^{4}$ School of Nursing, University of Nottingham, Nottingham, UK

${ }^{5}$ Palliative Medicine, North Manchester General Hospital, Manchester, UK ${ }^{6}$ Manchester Medical School, The University of Manchester, Manchester, UK ${ }^{7}$ Medicine, St Christopher's Hospice, London, UK

${ }^{8}$ Cicely Saunders Institute, King's College London School of Medical Education, London, UK

Twitter Bárbara Antunes@B CP Antunes, Ben Bowers@ Ben_Bowers_and Iain Lawrie $@ \bar{a}$ IainDr

Acknowledgements The authors wish to express their gratitude to our colleagues across the UK and Ireland who completed the questionnaire at a time of intense time pressure. We also wish to acknowledge the support of Prof Bee Wee (NHS England National Clinical Director for End of Life Care) and Dr Amy Proffitt (Vice-President of Association for Palliative Medicine) for their support of this study.

Contributors BA and SB designed and co-led the study: MPK, $\mathrm{RB}, \mathrm{RR}, \mathrm{AS}, \mathrm{IW}$ and $\mathrm{BB}$ contributed to the survey design; BB supported dissemination of the online survey; $\mathrm{BA}, \mathrm{IW}, \mathrm{BB}$ and SB conducted the data analysis; BA, BB, IW and SB drafted the paper; all the authors reviewed and commented on the draft paper and have approved this final version.

Funding BA, IW and SB are funded by the National Institute for Health Research (NIHR) Applied Research Collaboration East of England (ARC EoE) programme. The views expressed are those of the author(s) and not necessarily those of the NHS, the NIHR or the Department of Health and Social Care. BB is funded by the National Institute for Health Research (NIHR) School for Primary Care Research.

Map disclaimer The depiction of boundaries on this map does not imply the expression of any opinion whatsoever on the 
part of BMJ (or any member of its group) concerning the legal status of any country, territory, jurisdiction or area or of its authorities. This map is provided without any warranty of any kind, either express or implied.

Competing interests None declared.

Patient consent for publication Not required.

Provenance and peer review Not commissioned; internally peer reviewed.

Data availability statement No data are available. This is a preliminary analysis of the interim dataset obtained by 19 April 2020. Data collection is ongoing: a further paper is planned in the future once further responses have been received and a more detailed analysis of the dataset has been undertaken.

Open access This is an open access article distributed in accordance with the Creative Commons Attribution Non Commercial (CC BY-NC 4.0) license, which permits others to distribute, remix, adapt, build upon this work noncommercially, and license their derivative works on different terms, provided the original work is properly cited, appropriate credit is given, any changes made indicated, and the use is noncommercial. See: http://creativecommons.org/licenses/by-nc/4. $0 /$.

\section{ORCID iDs}

Bárbara Antunes http://orcid.org/0000-0003-1655-7391

Ben Bowers http://orcid.org/0000-0001-6772-2620

Stephen Barclay http://orcid.org/0000-0002-4505-7743

\section{REFERENCES}

1 National Institute for Health and Care Excellence. Care of dying adults in the last days of life [NG31]. Available: https:// www.nice.org.uk/guidance/ng31/resources/care-of-dyingadults-in-the-last-days-of-life-pdf-1837387324357 [Accessed 16 Apr 2020].

2 Bowers B, Ryan R, Kuhn I, et al. Anticipatory prescribing of injectable medications for adults at the end of life in the community: a systematic literature review and narrative synthesis. Palliat Med 2019;33:160-77.

3 Wilson E, Morbey $\mathrm{H}$, Brown J, et al. Administering anticipatory medications in end-of-life care: a qualitative study of nursing practice in the community and in nursing homes. Palliat Med 2015;29:60-70.

4 National Institute for Health and Care Excellence. Care of dying adults in the last days of life [QS144], 2017. Available: https://www.nice.org.uk/guidance/qs144/chapter/Qualitystatement-3-Anticipatory-prescribing [Accessed 16 Apr 2020].

5 National Institute for Health and Care Excellence. COVID-19 rapid guideline: managing symptoms (including at the end of life) in the community [NG163]. Available: https://www.nice. org.uk/guidance/ng163/resources/covid19-rapid-guidelinemanaging-symptoms-including-at-the-end-of-life-in-thecommunity-pdf-66141899069893 [Accessed 3 April 2020].

6 GIG Cymru NHS Wales. CARer-Administration of as needed subcutaneous medication for common breakthrough symptoms in home-based dying people in Wales (the CARiAD package). Available: https://www.wales.pallcare.info/files/docs/CARiAD\% 20Package/A\%20-\%20CARiAD\%20for\%20Covid-19\% 20policy\%20v1.0\%2020\%20March\%202020.pdf [Accessed 20 Mar 2020].

7 Health Improvement Scotland. Alternatives to regular medication normally given via a syringe driver when this is not available. Available: https://www.palliativecareguidelines.scot. nhs.uk/guidelines/symptom-control/alternatives-to-regularmedication-normally-given-via-a-syringe-pump-when-this-isnot-available.aspx [Accessed 9 Apr 2020].

8 Healthcare Improvement Scotland. Scottish palliative care guidelines: anticipatory prescribing. Available: www.palliati vecareguidelines.scot.nhs.uk/guidelines/pain/AnticipatoryPrescribing.aspx [Accessed 22 Apr 2020].
9 Wilson E, Seymour J, Seale C. Anticipatory prescribing for end of life care: a survey of community nurses in England. Primary Health Care 2016;26:22-7.

10 Rosenberg JP, Bullen T, Maher K. Supporting family caregivers with palliative symptom management: a qualitative analysis of the provision of an emergency medication kit in the home setting. Am J Hosp Palliat Care 2015;32:484-9.

11 Victoria State Government. Anticipatory medications, 2017. Available: https://www2.health.vic.gov.au/hospitals-and-healthservices/patient-care/end-of-life-care/palliative-care/ready-forcommunity/anticipatory-medicines [Accessed 22 Apr 2020].

12 Ministry of Health. Te Ara Whakapiri: principles and guidance for the last days of life, 2017. Available: https://www.health. govt.nz/system/files/documents/publications/te-ara-whakapiriprinciples-guidance-last-days-of-life-apr17.pdf [Accessed 22 Apr 2020].

13 Yap R, Akhileswaran R, Heng CP, et al. Comfort care kit: use of nonoral and nonparenteral rescue medications at home for terminally ill patients with swallowing difficulty. J Palliat Med 2014;17:575-8.

14 Bishop MF, Stephens L, Goodrich M, et al. Medication kits for managing symptomatic emergencies in the home: a survey of common hospice practice. J Palliat Med 2009;12:37-44.

15 Leigh AE, Burgio KL, Williams BR, et al. Hospice emergency kit for veterans: a pilot study. J Palliat Med 2013;16:356-61.

16 Staats K, Tranvåg O, Grov EK. Home-Care nurses' experience with medication kit in palliative care. J Hosp Palliat Nurs 2018;20:E1-9.

17 Office for national statistics. Available: https://www.ons.gov. uk/peoplepopulationandcommunity/birthsdeathsandmarriages/ deaths/bulletins/deathsregisteredweeklyinenglandandwalesp rovisional/weekending [Accessed 27 Apr 2020].

18 As many as half of Europe's COVID-19 deaths were people in long-term care facilities. Available: https://www.businessinsider. com/half-europes-covid-19-deaths-in-long-term-care-facilities2020-4? $\mathrm{r}=\mathrm{US} \& I R=\mathrm{T}$ [Accessed 26 Apr 2020].

19 Bowers B, Pollock K, Barclay S. Administration of end-of-life drugs by family caregivers during covid-19 pandemic. BMJ 2020;369:m1615.

20 Hill A. Families expected to provide palliative care during coronavirus crisis - NHS. Available: https://www.theguardian. com/society/2020/apr/18/families-expected-to-providepalliative-care-during-coronavirus-pandemic-nhs [Accessed 18 Apr 2020].

21 Ryan R, Bowers B, Spathis A, et al. 11 how is anticipatory prescribing in community end of life care governed in the UK? A content analysis of national and local guidance documents. BMJ Supp \& Palliat Care 2020;10:A4-5.

22 Faull C, Windridge K, Ockleford E, et al. Anticipatory prescribing in terminal care at home: what challenges do community health professionals encounter? BMJ Support Palliat Care 2013;3:91-7.

23 Perkins E, Gambles M, Houten R, et al. The care of dying people in nursing homes and intensive care units: a qualitative mixed-methods study. Health Serv Deliv Res 2016;4:1-410.

24 Bowers B, Redsell SA. A qualitative study of community nurses' decision-making around the anticipatory prescribing of end-oflife medications. J Adv Nurs 2017;73:2385-94.

25 Bowers B, Barclay SS, Pollock K, et al. General Practitioners' decisions about prescribing end-of-life anticipatory medications: a qualitative study. Br J Gen Pract 2020.

26 Jansen K, Haugen DF, Pont L, et al. Safety and effectiveness of palliative drug treatment in the last days of Life-A systematic literature review. J Pain Symptom Manage 2018;55:508-21.

27 Twycross R, Wilcock A, Howard P. Palliative care formulary. Nottingham: Pharmaceutical Press, 2018.

28 Poolman M, Shuler A. CARer-Administration of as needed subcutaneous medication for common breakthrough symptoms in home-based dying people in Wales (the CARiAD package), 
2020. Available: https://www.wales.pallcare.info/files/docs/ CARiAD\%20Package/A\%20-\%20CARiAD\%20for\%20Covid19\%20policy\%20v1.0\%2020\%20March\%202020.pdf [Accessed $20 \mathrm{Mar}$.

29 Lee L, Howard K, Wilkinson L, et al. Developing a policy to empower informal carers to administer subcutaneous medication in community palliative care; a feasibility project. Int J Palliat Nurs 2016;22:369-78.

30 Israel F, Reymond L, Slade G, et al. Lay caregivers' perspectives on injecting subcutaneous medications at home. Int J Palliat Nurs 2008;14:390-5.

31 Healy S, Israel F, Charles MA, et al. An educational package that supports laycarers to safely manage breakthrough subcutaneous injections for home-based palliative care patients: development and evaluation of a service quality improvement. Palliat Med 2013;27:562-70.

32 Kirchherr J, Charles K. Enhancing the sample diversity of Snowball samples: recommendations from a research project on anti-dam movements in Southeast Asia. PLoS One 2018;13:e0201710.

33 Eysenbach G. Improving the quality of web surveys: the checklist for reporting results of Internet E-Surveys (cherries). $J$ Med Internet Res 2004;6:e34.

34 Harrop E, Morgan F, Byrne A, et al. "It still haunts me whether we did the right thing": a qualitative analysis of free text survey data on the bereavement experiences and support needs of family caregivers. BMC Palliat Care 2016;15:92.

35 Healy S, Israel F, Charles M, et al. Laycarers can confidently prepare and administer subcutaneous injections for palliative care patients at home: a randomized controlled trial. Palliat Med 2018;32:1208-15.

36 Wilson E, Caswell G, Turner N, et al. Managing medicines for patients dying at home: a review of family caregivers' experiences. J Pain Symptom Manage 2018;56:962-74.

37 Payne S, Turner M, Seamark D, et al. Managing end of life medications at home--accounts of bereaved family carers: a qualitative interview study. BMJ Support Palliat Care 2015;5:181-8.

38 The human medicines regulations, 2012. Available: http:// www.legislation.gov.uk/uksi/2012/1916/contents/made [Accessed 28 Apr 2020].

39 National Institute for Health and Care Excellence. Managing medications in care homes [SC1]. Available: https://www.nice. org.uk/guidance/sc1 [Accessed 28 Apr 2020].

40 Department of Health \& Social Care. Novel coronavirus (COVID-19) standard operating procedure: running a medicines re-use scheme in a care home or hospice setting. Available: https://www.gov.uk/government/publications/ coronavirus-covid-19-reuse-of-medicines-in-a-care-home-orhospice [Accessed 29 Apr 2020]. 